\title{
ANALISIS POWER BUDGET JARINGAN KOMUNIKASI SERAT OPTIK DI PT.TELKOM AKSES MAKASSAR
}

\author{
Rahmania ${ }^{1}$ \\ ${ }^{1}$ Program Studi Teknik Elektro Fakultas Teknik Universitas Muhammadiyah Makassar \\ e-mail : rahmanialunismuh.ac.id ${ }^{1}$
}

\begin{abstract}
From a fiber optic communication system, we will not be separated from the attention of the power budget (Power budget). Optical communication system running well and smoothly if not lack of power budget (Power budget) and Rise time budget (Rise time budget). In this thesis will only discuss about the calculation and analysis of Power budget. Power budget analysis is very important to be done regularly to assess and evaluate the feasibility of a fiber optic communication network. Power budget analysis on this thesis will be done for communications networks that are within the coverage area of PT. Telkom Access Fiber Zone KTI Makassar and there are only 3 Links to be analyzed, from the three calculations Loss that the condition of the three communication networks that are within the coverage area of PT. Telkom Access Fiber Zone KTI Makassar still produces small Loss value except for core number 8,12,13,15 at Link 1 ODPBal-Fef, number 5,8,10 at Link 2 and number 1,2,6,8, 10.12 on Link 3 which is a special case and from the calculation of Power Budget also seen that the value of Loss measurement results are still within the limits of the standardization is determined and the value of Margin produced by the three access networks is still very positive and still within limits standardization. Based on data measurement results and calculation results can be predicted that the growth of link quality degradation will occur at the fastest link 2 where this link will experience the addition of attenuator or new repeater faster than other links.
\end{abstract}

Intisari-Dari suatu sistem komunikasi serat optik, kita tidak akan lepas dari perhatian anggaran daya (Power budget). Sistem komunikasi optik berjalan baik dan lancar apabila tidak kekurangan anggaran daya (Power budget) dan anggaran waktu bangkit (Rise time budget). Penelitian bertujuanuntuk mengetahui kelayakakan jaringan akses pada cakupan area PT. Teklkom Akses Makassar dengan menganalisis Power budget.Analisis Power budget ini sangat penting dilakukan secara berkala untuk menilai dan mengevaluasi kelayakan suatu jaringan komunikasi serat optik. Analisis Power budget dilakukan untuk jaringan komunikasi yang berada dalam cakupan area PT. Telkom Akses Fiber Zone KTI Makassar dan hanya ada 3 Link yang akan dianalisis,dari ke-tiga perhitungan Loss bahwa kondisi ke-tiga jaringan komunikasi yang berada dalam cakupan area PT. Telkom Akses Fiber Zone KTI Makassar masih menghasilkan nilai Loss yang kecil kecuali untuk core nomor 8,12,13,15 pada Link 1 ODP-Bal-Fef, nomor 5,8,10 pada Link 2 dan nomor 1,2,6,8,10,12 pada Link 3 yang merupakan special case dan dari perhitungan Power Budget juga terlihat bahwa nilai Loss hasil pengukuran masih berada dalam batas standarisasi yang ditentukan dan nilai Margin yang dihasilkan oleh ke-tiga jaringan akses tersebut masih sangat positif dan masih berada dalam batas standarisasi. Berdasarkan data hasil pengukuran dan hasil analisis perhitungan tersebut dapat diprediksi bahwa pertumbuhan degradasi kualitas link paling cepat akan terjadi pada link 2 dimana link ini akan mengalami penambahan atenuator atau repeater baru yang lebih cepat dari link lainnya.

Kata kunci : Serat optik, Power budget, jaringan 


\section{PENDAHULUAN}

\section{Latar Belakang Masalah}

Di era masyarakat modern ini dibutuhkan teknologi informasi komunikasi berkecepatan tinggi dan berkapasitas besar dalam bidang telekomunikasi untuk mendukung perkembangan teknologi informasi yang semakin berkembang saat ini.Serat optik sebagai media transmisi mampu meningkatkan pelayanan sistem komunikasi data, suara, dan vidio. Penerapan serat optik sebagai media transmisi dalam bidang telekomuniksi telah memberikan berbagai keuntungan dan manfaat baik dari segi transfer data maupun dari segi ekonomi karena dapat mengurangi penggunaan banyak kabel. Penerapan kabel serat optik sebagai media transmisi dalam dunia telekomunikasi merupakan salah satu solusi dari berbagai permasalahan yang ada. Akan tetapi pada saat serat optik di pilih sebagai media transmisi, perlu dilakukan suatu perhitungan dan analisis power budget (anggaran daya) sebelum serat optik digunakan dalam sebuah jaringan telekomunikasi agar suatu sistem komunikasi optik dapat berjalan dengan lancar dan baik, seperti adanya rugi-rugi transmisi (Loss) pada kabel serat optik yang dapat menurunkan kualitas transmisi.Pengetahui kualitas suatu jaringan, biaya, dan prediksi lamanya usia suatu jaringan telekomunikasi serta untuk mengetahui kelayakan suatu jaringan dalam mengirim informasi ini sangatlah penting

\section{Rumusan Masalah}

Berdasakan latar belakang diatas maka rumusan masalah pada penelitian ini adalah:

1) Bagaimana kondisi jaringan komunikasi yang berada pada cakupan area PT. Telkom Akses Makassar?

2) Bagaimana kelayakan jaringan akses pada cakupan area PT. Telkom Akses Makassar dengan menganalisis power budget (anggaran daya)?

\section{Tujuan Penelitian}

1) Untuk mengetahui kondisi jaringan komunikasi yang berada pada cakupan area PT. Telkom Akses Makassar.

2) Untuk mengetahui kelayakan jaringan akses pada cakupan area 
PT. Telkom Akses Makassar dengan menganalisis power budget.

\section{KAJIAN PUSTAKA}

\section{Serat Optik}

Serat optik adalah saluran transmisi atau sejenis kabel yang terbuat dari kaca atau plastik yang sangat halus dan lebih kecil dari sehelai rambut, dan dapat digunakan untuk mentransmisikan sinyal cahaya dari suatu tempat ke tempat lain. Sumber cahaya yang digunakan biasanya adalah laser atau LED. Kabel ini berdiameter lebih kurang 120 mikrometer. Cahaya yang ada di dalam serat optik tidak keluar karena indeks bias dari kaca lebih besar daripada indeks bias dari udara, karena laser mempunyai spektrum yang sangat sempit. Kecepatan transmisi serat optik sangat tinggi sehingga sangat bagus digunakan sebagai saluran komunikasi.

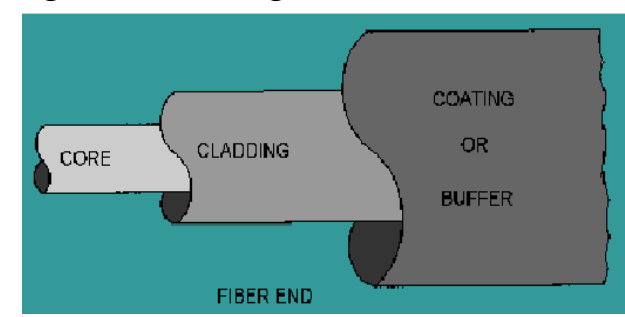

Gambar 1. Struktur fiber optic

Komponen Transmisi Serat Optik
Suatu transmisi serat optik terdiri dari tiga komponen utama yaitu perangkat pengirim (Tx), perangkat penerima $(\mathrm{Rx})$, dan media transmisi. Ketiga komponen ini mutlak dimiliki dalam suatu dasar transmisi serat optik.

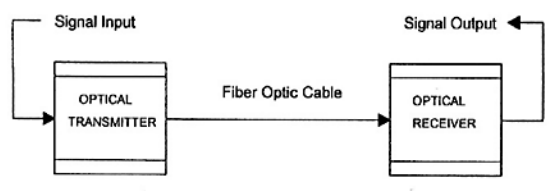

Gambar 2. Skema Transmisi Serat

$$
\text { Optik }
$$

\section{Cara Kerja Serat Optik}

Prinsip kerja serat optik berdasarkan hukum Snellius yaitu jika seberkas sinar masuk pada suatu ujung serat optik (media yang transparan) dengan sudut kritis dan sinar itu datang dari medium yang mempunyai indeks bias lebih kecil dari udara menuju inti fiber optik (kuartz murni) yang mempunyai indeks bias yang lebih besar maka seluruh sinar akan merambat sepanjang inti (core) serat optik menuju ujung yang satu. Disini cladding (lihat gambar 2.3) berguna untuk memantulkan kembali cahaya kembali ke core.

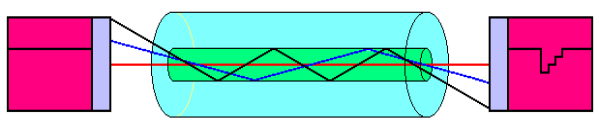


Gambar 3. Perambatan cahaya pada serat optik yang lurus

\section{Jenis Serat Optik}

Berdasarkan jumlah mode yang dapat dilewatkan, serat optik dibagi menjadi 2 jenis secara umum yaitu

1) Serat optik jenis tunggal berarti hanya mampu melewatkan satu mode saja. Hal ini disebabkan oleh ukuran intinya yang relatif kecil serta kecilnya nilai beda indeks $(\Delta)$ antara inti dan cladding. Ukuran diameter inti serat optik jenis tunggal berkisar antara 8-10 $\mu \mathrm{m}$.

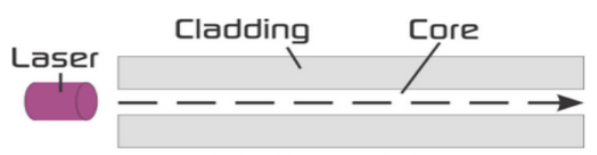

Gambar 4.fiber optik tunggal

Dengan hanya melewatkan satu mode saja berarti pada serat optik jenis tunggal ini tidak ditemukan dispersi modal seperti pada serat optik ganda.Hal ini berdampak positif terhadap penggunaan serat optik jenis tunggal karena juga berarti peningkatan bandwidth. Selain itu, baik dari segi bandwidth maupun jarak transmisi, serat optik jenis tunggal lebih unggul dibandingkan dengan serat optik jenis ganda, karena jarak transmisinya sangat jauh dan bandwidthnya juga besar.

2) Serat optik jenis ganda tidak memiliki diameter inti 50-80 micron dan memiliki keunggulan di segi bandwidth karena ada banyak mode yang dilewatkan oleh suatu serat optik sehingga kemungkinan untuk terjadi dispersi juga semakin besar yang mengakibatkan terjadi pelebaran pulsa. Serat optik jenis ganda memilii dua jenis yaitu step index dan graded index. Perbedaan keduanya terletak pada keseragaman indeks bias.

\section{Pelemahan}

Pelemahan (Attenuation) cahaya sangat penting diketahui terutama dalam merancang sistem telekomunikasi serat optik itu sendiri. Pelemahan cahaya dalam serat optik adalah adanya penurunan rata-rata daya optik pada kabel serat optik, biasanya diekspresikan dalam decibel ( $\mathrm{dB}$ ) tanpa tanda negatif. Berikut ini beberapa hal yang menyumbang kepada pelemahan cahaya pada serat optik: 
1) Penyerapan

(Absorption) Kehilangan cahaya yang disebabkan adanya kotoran dalam serat optik.

2) Penyebaran (Scattering).

3) Kehilangan radiasi (radiative losses).

Suatu sinyal optik yang ditransmisikan didalam serat optik tentu akan mendapat pengaruh dari berbagai aspek. Pengaruh tersebut akan mengakibatkan adanya pelemahan daya sinyal sebagai konsekuensi dari adanya daya yang hilang (loss) pada sinyal transmisi tersebut. Rugi-rugi daya ini dapat terjadi baik karena keadaan serat optik tersebut ataupun akibat perlakuan dari luar terhadap serat optik tersebut, terutama pada penyambungan. Rugirugi daya secara umum terdiri dari atenuasi kabel $(\alpha) \mathrm{dB} / \mathrm{km}$, rugi- rugi akibat penyambungan seperti rugi konektor, maupun splice. Adapun halhal yang menyebabkan rugi-rugi daya terutama atenuasi adalah fenomenafenomena seperti pembelokan, pembengkokan, absorpsi, maupun hamburan. Dengan adanya pelemahan daya ini tentunya akan merubah besar daya yang dikirim dengan data yang diterima. Perhitungan link budget atau power budget menjadi salah satu pertimbangan penting dalam perencanaan jaringan serat optik. Tujuan dilakukannya perhitungan power budget adalah untuk menentukan apakah komponen dan parameter disain yang dipilih dapat menghasilkan daya sinyal di penerima sesuai dengan tuntutan persyaratan perfomansi yang diinginkan serta untuk melakukan proses evaluasi secara rutin. Perhitungan power budget dilakukan berdasarkan keadaan jaringan seperti:

a. Daya minimum transmiitter (PS) $(\mathrm{dBm})$

b. Sensitivitas minimum receiver $(\mathrm{PR})$ $(\mathrm{dBm})$

c. Atenuasi $(\alpha)(\mathrm{dB} / \mathrm{km})$

d. Rugi-rugi penyambungan seperti rugi konektor (Loss conn $_{\text {) dan splice }}$ $($ Losssplice) $(\mathrm{dB})$

e. Margin saluran (Lossmargin)(dB)

f. Jarak sambungan $(l)(\mathrm{km})$

\section{Power Budget}

Power budget dalam komunikasi serat optik adalah daya yang tersedia dipengiriman (Ptx) pada komunikasi serat optik yang disesuaikan dan dialokasi dengan kerugian seprti rugi 
Vertex Elektro, Vol. 01, No. 02 Tahun 2019

penyambung (splice), redaman serat, rugi konektor, rugi-rugi lainny: ..... penguat (EDFA) untuk mem bahwa kekuatan daya sinyal tersediah cukup pada penerim sistem tersebut layak.. Karena an daya menjamin agar penerima menerima daya optik sinyal diperlukan untuk mendapatkan $\mathrm{b}$ rate (BER) yang diin Perhitungan dan analisis power merupakan salah satu metode mengetahui perfomansi suatu janngan. Tujuan dilakukannya perhitungan power budget adalah untuk menentukan apakah komponen dan parameter disain yang dipilih dapat menghasilkan daya sinyal di penerima sesuai dengan tuntutan persyaratan perfomansi yang diinginkan.

\section{METODE PENELITIAN}

\section{Waktu dan Tempat Penelitian}

Penelitian ini dilaksanakan selama 4 bulan, mulai dari bulan November 2017 sampai dengan Februari 2018.Lokasi penelitian di PT.Telkom Akses Makassar.

Alur penelitian :

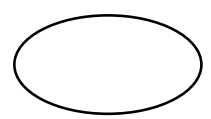

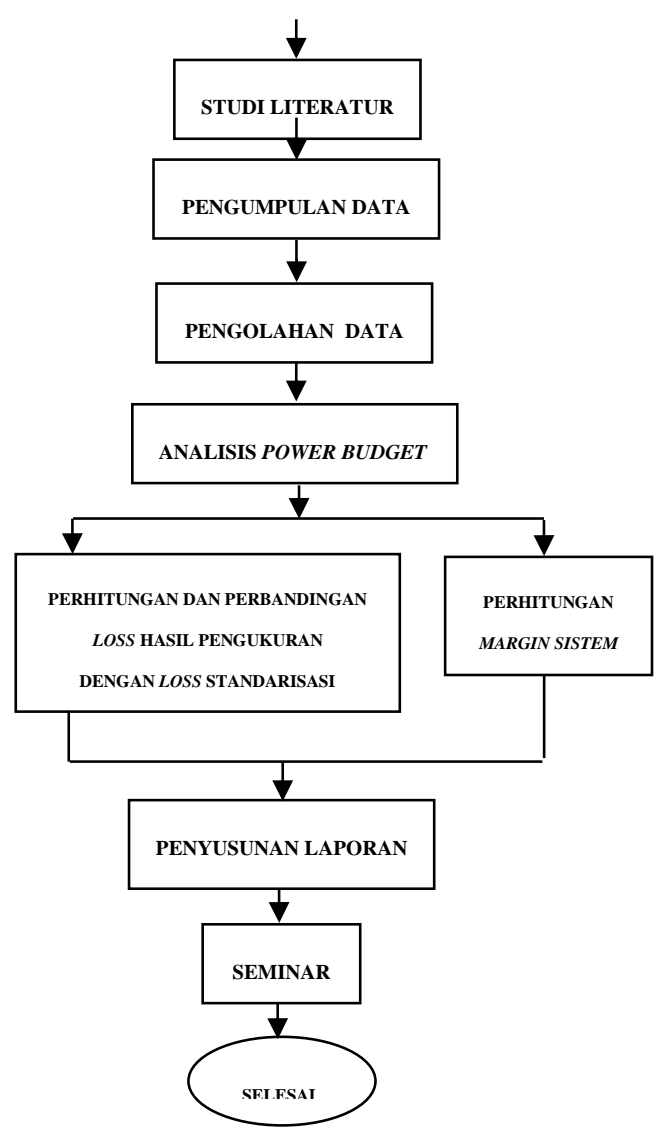

HASIL DAN PEMBAHASAN

Dalam melakukan perhitungan power budget PT. TELKOM memiliki standar untuk membatasi loss yang boleh ada pada suatu link transmisi. Standar tersebut merupakan acuan yang dipergunakan oleh PT. TELKOM pada saat awal perencanaan dan pembangunan jaringan. Standar ini menentukan batas maksimum untuk fiber loss, splice loss dan connector loss yang nilai-nilainya telah disebutkan. Batas maksimum inilah yang dipakai oleh PT. TELKOM pada 
saat melakukan perencanaan suatu jaringan. Oleh karena itu, loss dari hasil pengukuran harus memiliki nilai di bawah batas maksimum tersebut untuk mendapatkan unjuk kerja yang baik.

Pengukuran dilakukan dengan mempergunakan alat optical time domain reflectometer (OTDR) dari PT.Telkom Akses Makassar (hasil pengukuran dapat dilihat pada bagian lampiran). Sedangkan, untuk melihat perfomansi dari sisi power budget selain membandingkan loss dengan melakukan pengukuran di lapangan, hasil evaluasi juga dapat diperkuat dengan mencari margin sistem melalui perhitungan. Margin diperlukan untuk mengantisipasi adanya perubahan parameter komponen karena usia operasi sehingga menyebabkan degradasi. Margin harus menunjukkan nilai positif. Dengan kata lain gain dari sistem harus lebih besar atau sama dengan total loss. Perhitungan margin mensubtitusi rumus yang ada pada bab 2 yaitu ; System Gain $(\mathrm{Gs})=\mathrm{Pt}-\mathrm{MRP}$ dan $\mathrm{M}=\mathrm{Gs}-$ Lo.Untuk tiap jenis Loss yang digunakan di PT. Telkom Akses Fiber Zone KTI Makassar

Fiber loss $\quad: 0,35 \mathrm{~dB} / \mathrm{km}$
Splice Loss $\quad$ : 0,1 dB

Connector loss : $0,25 \mathrm{~dB}$

Data-data yang dipergunakan untuk mencari nilai margin adalah total loss, PT. Telkom Akses Fiber Zone KTI Makassar tidak memiliki alat untuk mengukur daya sehingga datadata untuk daya diperoleh dari sumber lain yaitu dari kriteria parameter perangkat yang dipakai. Jaringan akses di STO Tebet memakai perangkat SDH SDT1 yang memiliki kriteria parameter optical interface tertentu.Pada penyelesaian untuk perhitungan margin ini menggunakan persamaan (11):

$\mathrm{M}=(\mathrm{Pt}-\mathrm{MRP})-\mathrm{LodB}$

$M=(0-(-38))-0,54 \mathrm{~dB}$

$M=38-0,54 \mathrm{~dB}$

$\mathrm{M}=37,46 \mathrm{dBm}$

dengan persamaan (10), dapat dilakukan perhitungan total loss dari standarisasi. Berikut perhitungan total loss :

Lo (Total rugi-rugi)

$=$ D.Lf + Nc.Lc + Ns.Ls + Lps dB $=(0,4346.0,35)+(2 \cdot 0,25)+(1.0,1)$ $\mathrm{dB}$ $=0,1521+0,5+0,1 \mathrm{~dB}$ 
$=0,7521 \mathrm{~dB}$

Data-data hasil perhitungan dan pengukuran untuk evaluasi power budgetdapat diringkas kedalam tabel 5 , 6, dan 7 .

Tabel 5 Data hasil evaluasi Power

\section{Buget Link ODP-Bal-Fef}

\begin{tabular}{|c|c|c|c|c|}
\hline No. & $\operatorname{Jarak}(\mathrm{km})$ & Loss Hasil Pengukuran (AB) & Loss Standarisas (dB) & Margin Sistem (AB) \\
\hline 1 & 0,4346 & 0,54 & 0,75211 & 37,46 \\
\hline 2 & 0,4998 & 0,37 & 0,77493 & 37,63 \\
\hline 3 & 0,5 & 0,54 & 0,775 & 37,46 \\
\hline 4 & 0,5002 & 0,6 & 0,77507 & 37,4 \\
\hline 5 & 0,5839 & 0,58 & 0,804365 & 37,42 \\
\hline 6 & 0,7659 & 0,43 & 0,868065 & 37,57 \\
\hline 7 & 0,8618 & 0,9 & 0,00163 & 37,1 \\
\hline 8 & 0,9709 & 1,58 & 0,939815 & 36,42 \\
\hline 9 & 1,0576 & & & \\
\hline 10 & 1,1863 & 0,92 & 1,015205 & 37,08 \\
\hline 11 & 1,314 & & & \\
\hline 12 & 1,3368 & 1,32 & 1,06788 & 36,68 \\
\hline 13 & 1,3957 & 1,13 & 1,088495 & 36,87 \\
\hline 14 & 1,5458 & 0,91 & 1,14103 & 37,09 \\
\hline 15 & 1,6452 & 3,06 & 1,17582 & 34,94 \\
\hline
\end{tabular}

Tabel 6 Data hasil evaluasi Power

Buget Link ODP-PNK-Fat

\begin{tabular}{|c|c|c|c|c|}
\hline No. & $\operatorname{Jarak}(k \mathrm{~m})$ & Loss Hasil Pengukuran (dB) & Loss Standarisasi (dB) & Margin Sistem lo \\
\hline 1 & 0,6919 & 0,67 & 0,742165 & 37,33 \\
\hline 2 & 0,9394 & 0,56 & 0,82879 & 37,44 \\
\hline 3 & 1,2092 & 0,82 & 0,92322 & 37,18 \\
\hline 4 & 1,2454 & 0,88 & 0,93589 & 37,12 \\
\hline 5 & 1,3789 & 1,1 & 0,982615 & 36,9 \\
\hline 6 & 1,4508 & 0,63 & 1,00778 & 37,37 \\
\hline 7 & 1,4715 & 0,72 & 1,015025 & 37,28 \\
\hline 8 & 1,5866 & 1,14 & 1,05531 & 36,86 \\
\hline 9 & 1,6011 & 0,37 & 1,060385 & 37,63 \\
\hline 10 & 1,6578 & 1,77 & 1,08023 & 36,23 \\
\hline 11 & 1,7417 & 0,91 & 1,109595 & 37,09 \\
\hline 12 & 1,9772 & 1,13 & 1,19202 & 36,87 \\
\hline 13 & 2,0937 & 1,15 & 1,232795 & 36,85 \\
\hline 14 & 2,2139 & 0,55 & 1,274865 & 37,45 \\
\hline
\end{tabular}

Tabel 7 Data hasil evaluasi Power Buget Link ODP-PNK-FAV

\begin{tabular}{ccccc} 
No. & Jark (km) & Loss Hasil Pengukuran (dB) & Loss Standarisasi (dB) & Margin Sistem (dB) \\
\hline 1 & 0,243 & 0,84 & 0,68505 & 37,16 \\
\hline 2 & 0,4192 & 1,07 & 0,74672 & 36,93 \\
\hline 3 & 0,4912 & 0,47 & 0,77192 & 37,53 \\
\hline 4 & 0,5511 & 0,24 & 0,792885 & 37,76 \\
\hline 5 & 0,6471 & 0,34 & 0,266485 & 37,66 \\
\hline 6 & 0,7677 & 1,25 & 0,868695 & 36,75 \\
\hline 7 & 0,8413 & 0,73 & 0,894455 & 37,27 \\
\hline 8 & 0,8785 & 1,03 & 0,907475 & 36,97 \\
\hline 9 & 1,288 & 0,32 & 0,96008 & 37,68 \\
\hline 10 & 1,0377 & 0,98 & 0,963195 & 37,02 \\
\hline 11 & 1,1493 & 0,82 & 1,002255 & 37,18 \\
\hline 12 & 1,2043 & 3,38 & 1,021505 & 34,62 \\
\hline 13 & 1,243 & 0,28 & 1,03505 & 37,72 \\
\hline 14 & 1,3333 & 0,71 & 1,066555 & 37,29 \\
\hline 15 & 1,3566 & 0,39 & 1,07481 & 37,61 \\
\hline 16 & 1,4547 & 1,07 & 1,109145 & 36,93
\end{tabular}

\section{Analisis Power Budget}

Pada saat melakukan evaluasi dan analisis maka yang perlu diperhatikan adalah Margin sistem yang dihasilkan masih positif atau tidak dan perbandingan antara loss hasil pengukuran dan loss perhitungan berdasarkan standarisasi yang ditetapkan oleh PT TELKOM. Perbandingan yang baik adalah nilai loss hasil pengukuran harus lebih kecil daripada loss dari hasil perhitungan berdasarkan standarisasi.

Dari data pada Tabel 5 dapat terlihat bahwa loss dari hasil pengukuran hanya berkisar antara 0,37 s/d 3,06 dan loss dari hasil perhitungan berdasarkan standarisasi berkisar antara 0,75211 s/d 1,17582. Sedangkan 
Margin sistem yang didapat berkisar antara 34,49 s/d 37,57. Hal ini menunjukkan bahwa loss hasil pengukuran masih relatif kecil bila dibandingkan dengan loss standarisasi PT TELKOM meskipun ada beberapa diatas standarisasi. Selain itu, margin sistem yang dihasilkan juga masih sangat positif. Dimana nilai margin yang baik adalah $38 \mathrm{dBm}$. Dari kedua fakta tersebut dapat kita simpulkan bahwa kondisi Link ODP-Bal-Fef masih bagus. Untuk Lebih jelas lihat pada Gambar 4 dibawah ini.

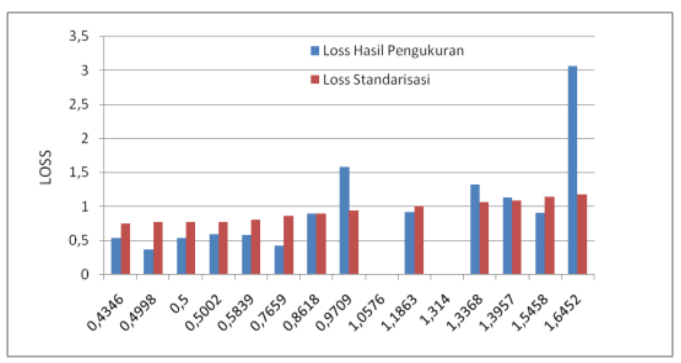

Gambar 4. Perbandingan Loss Hasil Pengukuran dan Loss Standarisasi

Dari gambar 4.4 terlihat bahwa peningkatan nilai loss tidak beraturan, namun hampir relatif sama. Akan tetapi pada jaringan akses ini terdapat 4 buah core yang memiliki nilai loss hasil pengukuran yang sangat besar yaitu core $8,12,13$ dan 15 dengan nilai loss sebesar 1,13 dB s/d 3,06 dB. Nilai ini sangat buruk mengingat nilai loss hasil perhitungan standarisasi berkisar 0,75 s/d 1,175 dB. Hal ini dapat disebabkan oleh kondisi dari core serat optik itu sendiri dimana terjadi cacat pada saat pabrifikasi atau bisa juga disebabkan oleh kondisi lingkungan dan bisa juga terjadi karena kesalahan pada saat instalasi kabel (misalnya kabelnya ada yang terjepit sehingga core-core yang berada pada bagian paling luar mengalami retak atau pecah). Penyebab lainnya juga bisa terjadi karena core tersebut tidak terhubung dengan baik disisi penerima sehingga ada daya yang hilang. Khusus untuk core 15 ini merupakan kasus spesial, melihat loss yang dihasilkan sangat tinggi dari standarisasi dan diprediksikan core 15 ini akan mengalami degradasi yang lebih cepat atau dengan kata lain masa aktif core ini akan lebih cepat habis, sedangkan loss terkecil terjadi pada core nomor 2 dengan jarak link 0,4998 m. Adanya peningkatan penurunan kualitas link juga disebabkan oleh halhal yang telah disebutkan pada bab 2 . Pada diagram diatas juga terdapat 9 core yang memiliki nilai loss berada dibawah standar loss yang ditetapkan sehingga tidak terlalu berpengaruh terhadap kualitas jaringan. Namun peningkatan loss dapat terjadi dan 
secara fisik sebenarnya penyebab ke-9 link ini sama yaitu disebabkan oleh bertambahnya usia komponen itu sendiri, misalnya redaman konektor yang semakin besar, kepekaan optik yang semakin melemah, dan daya keluaran pengirim yang semakin menurun dan kualitas kabel optik yang banyak dipengaruhi oleh kondisi lingkungan sekitarnya. Selain itu, pada jaringan akses ini juga terdapat 2 core yang tidak terukur pada saat dilakukan proses pengukuran yaitu core 9 dan 11 . Hal ini disebabkan karena core tersebut tidak terhubung disisi penerima dengan kata lain core tersebut tidak aktif.

Dari data pada Tabel 6 dapat terlihat bahwa loss dari hasil pengukuran hanya berkisar antara 0,37 s/d 1,77 dan loss dari hasil perhitungan berdasarkan standarisasi berkisar antara 0,74216 s/d 1,2748. Sedangkan Margin sistem yang didapat berkisar antara 36,23 s/d 37,63. Hal ini menunjukkan bahwa loss hasil pengukuran masih relatif kecil bila dibandingkan dengan loss standarisasi PT TELKOM meskipun ada beberapa pengukuran diatas standarisasi. Selain itu, margin sistem yang dihasilkan juga masih sangat positif. Dimana nilai margin yang baik adalah $38 \mathrm{dBm}$. Dari kedua fakta tersebut dapat kita simpulkan bahwa kondisi Link ODP-PNK-Fat masih sangat bagus. Untuk Lebih jelas lihat pada Gambar 5. dibawah ini.

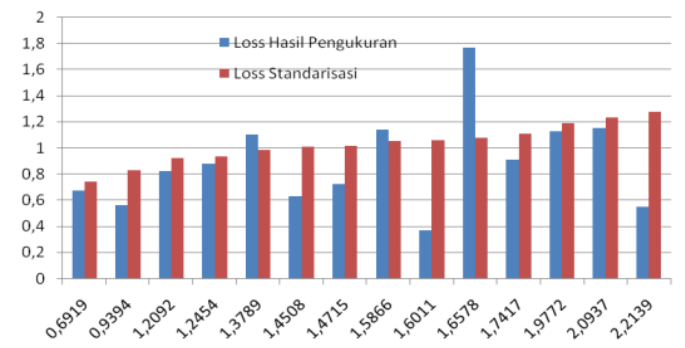

Gambar 5. Perbandingan Loss Hasil Pengukuran dan Loss Standarisasi

Dari gambar 5 terlihat bahwa peningkatan nilai loss tidak beraturan, namun hampir relatif sama. Untuk loss dari hasil pengukuran nilai loss yang terbesar hanya terjadi pada core nomor 10 dengan jarak link 1,6578 m, sedangkan loss terkecil terjadi pada core nomor 9 dengan jarak link 1,6011 m. Redaman link tersebut menjadi bertambah besar, hal ini menunjukkan adanya penurunan kualitas link. Secara fisik, hal ini disebabkan oleh bertambahnya usia komponen itu sendiri, misalnya redaman konektor yang semakin besar, kepekaan optik yang semakin melemah, dan daya keluaran pengirim yang semakin menurun dan kualitas kabel optik yang 
Vertex Elektro, Vol. 01, No. 02 Tahun 2019

banyak dipengaruhi oleh kondisi lingkungan sekitarnya.

Dari data pada Tabel 7. dapat terlihat bahwa loss dari hasil pengukuran hanya berkisar antara 0,24 s/d 3,38 dan loss dari hasil perhitungan berdasarkan standarisasi berkisar antara 0,6850 s/d 1,1091. Sedangkan Margin sistem yang didapat berkisar antara 34,62 s/d 37,72. Hal ini menunjukkan bahwa loss hasil pengukuran masih relatif kecil bila dibandingkan dengan loss standarisasi PT.TELKOM meskipun ada beberapa diatas standaisasi. Selain itu, margin sistem yang dihasilkan juga masih sangat positif. Dimana nilai margin yang baik adalah $38 \mathrm{dBm}$. Dari kedua fakta tersebut dapat kita simpulkan bahwa kondisi link ODP-Bal-FAV masih sangat bagus. Untuk Lebih jelas lihat pada Gambar 6 dibawah ini.

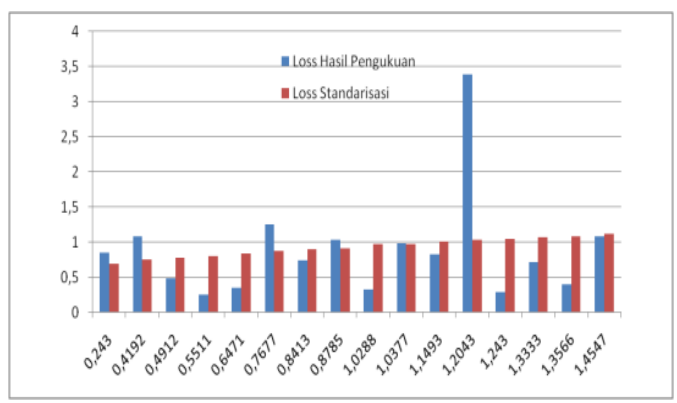

Gambar 6 Perbandingan Loss Hasil Pengukuran dan Loss Standarisasi
Dari gambar 6. diatas terlihat bahwa peningkatan nilai loss tidak beraturan, namun hampir relatif sama. Untuk loss dari hasil pengukuran nilai loss yang terbesar hanya terjadi pada core nomor 12 dengan jarak link 1,2043 m, sedangkan loss terkecil terjadi pada core nomor 4 dengan jarak link $0,5511 \mathrm{~m}$. Secara fisik, hal ini disebabkan oleh bertambahnya usia komponen itu sendiri.

\section{Perbandingan Power Budget antar} Link

Kemudian dengan melihat dan membandingkan ke-tiga nilai margin rata-rata tersebut akan terlihat jaringan akses mana yang memiliki margin yang paling positif atau baik dan jaringan akses mana yang paling rendah. Gambar 7 berikut adalah grafik perbandingan margin rata-rata ke-tiga jaringan akses atau link diatas.

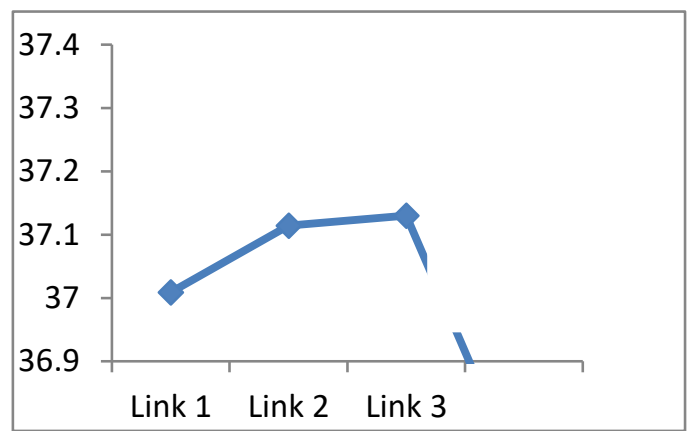

Gambar 7. Perbandingan Margin ratarata Sistem 
Dari Grafik diatas terlihat PENUTUP

bahwa link 3 (ODP-PNK-FAV) memiliki nilai margin rata yang paling baik yaitu 37,13 dB dan berikutnya adalah link 2 (ODP-PNK-Fat) yang memiliki nilai margin rata-rata 37,11 dB dan selanjutnya adalah link 1 (ODPBal-Fef) dengan nilai margin rata-rata sebesar 37,009dB, dimana margin rata-rata yang paling rendah. Walaupun link 1 memiliki nilai margin rata-rata yang paling rendah dari ke-tiga link tersebut, tidak berarti link 1 memiliki performansi yang jelek. Berdasarkan data hasil pengukuran tersebut dapat diprediksi bahwa pertumbuhan degradasi kualitas link paling cepat akan terjadi pada link 2 dimana link ini akan mengalami penambahan atenuator atau repeater baru yang lebih cepat dari link lainnya atau bahkan proeses instalasi baru yang lebih cepat.

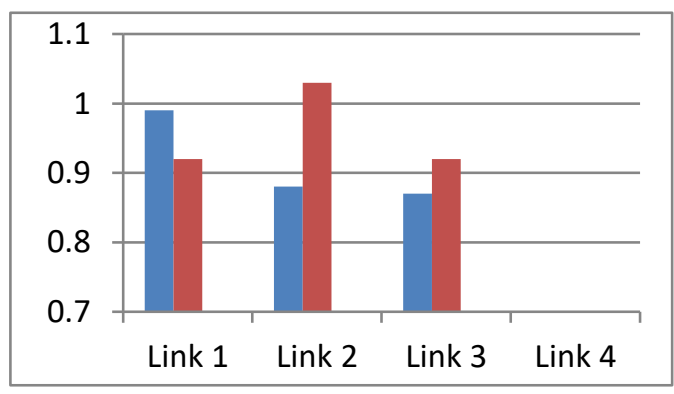

Gambar 9. Perbandingan loss ratarata hasil pengukuran dan dari standarisasi antar link.

\section{Kesimpulan}

1) Dari ke-tiga perhitungan Loss bahwa kondisi ke-tiga jaringan komunikasi yang berada dalam cakupan area PT. Telkom Akses Makassar masih menghasilkan nilai Loss yang kecil, kecuali untuknomor 8,12,13,15 pada Link 1 ODP-Bal-Fef, nomor 5,8,10 pada Link 2 dan nomor 1,2,6,8,10,12, pada Link 3.namun dalam hal ini, kondisi ke-tiga link sudah tidak layak.

2) Dari perhitungan Power Budget juga terlihat bahwa nilai Loss hasil pengukuran masih berada dalam batas standarisasi yang ditentukan dengan nilai Margin yang dihasilkan oleh ke-dua jaringan akses yaitu pada link 2 dan link 3 tersebut masih sangat positif dan masih berada dalam batas standarisasi. Namun pada link 1, loss pengukuran tidak berada dalam batas standarisasi. Dengan demikian dapat kita lihat bahwa berdasarkan perhitungan hasil analisis Power Budget ke-dua jaringan akses tesebut masih cukup 
baik dan layak, kecuali pada link 1 dimana jaringan aksesnya sudah tidak baik dan tidak layak.

\section{Saran}

1) Melalui skripsi ini diharapkan dapat memberi gambaran mengenai Power Budget dan penerapannya di jaringan transmisi.

2) Diharapkan melalui skripsi ini bisa dijadikan kedepan sebagai bahan penelitian oleh mahasiswa.

\section{DAFTAR PUSTAKA}

Auzaiy. 2008. “Analisis Power Budget Jaringan Komunikasi Serat Optik PT.Telkom di STO Jatinegara". Skripsi Jurusan Teknik Elektro Fakultas Teknik Universitas Indonesia.

Crisp,John Bary Elliot. “ Serat Optik: Sebuah Pengantar". Erlangga Jakarta 2006.

"FiberOptik",http://www.datacottage. com/nch/fibre.htm, Juni 2015 lab.binus.ac.id/pk/download/s erat optik.pdf,maret 2008.

Introduction to Fiber Optics Part 1 http://www.commspecial.com/ fiberguide.htm\#advantages, dia kses tanggal12 Februari 2006.
JosephC,"FiberOptic Communication

".http://howstuffworks.com,M aret2008.

Jambola Lucia. 2016 “ Simulasi Anggaran Daya Sistem Komunikasi Serat Optik Berbasis Matlab 7.5 ”. Jurnal Mahasiswa Teknik Elektro Telekomunikasi ITB.

Koonen, Ton. "Fibre_Optic Tecniques for Broadband Access Networks". Telektronik vol 101, Norway, 2005.

RahmanRivaldiMazhuri. 2015 “ Optical Time Domain Reflectometer (OTDR)". Materi dari PT.Telkom Akses Fiber Zone KTI Makassar.

Rogers, Alan. “ Understanding Optical Fiber Communications". Artech House, Norwood, 2001.

"SeratOptik",http://id.wikipedia.org/ wiki/serat_optik.htm, Juni 2014lab.binus.ac.id/pk/downlo ad/seratoptik.pdf,maret 2008 .

Hantoro, Gunadi Dwi. 2015. Fiber Optic. Bandung: Informatika.

Prasetia Dwi. 2009. Serat optik. Univesitas Sriwijaya Palembang. 